\title{
The effect of acid leaching conditions on enriching iron during comprehensive treatment of pyrite cinder
}

\author{
Wang Jiawei ${ }^{1,2, a}$, Li Anjing ${ }^{1,2, b}$, Wang Haifeng ${ }^{1,2, ~ c}$, Zhao Pingyuan 1, 2, d \\ (1. College of Materials and Metallurgy, Guizhou University, Guiyang 550025, China , 2. Guizhou \\ Provence Key Laboratory of Metallurgical Engineering and Energy Saving, Guiyang 550025, \\ China) \\ aw_j_wei@qq.com, ${ }^{\text {bleesilence@yeah.net, }{ }^{c} \mathrm{~mm} . h f w a n g @ g z u . e d u . c n,{ }^{d} \mathrm{~mm} . p y z h a o @ g z u . e d u . c n}$
}

Keywords: pyrite cinder, comprehensive utilization, iron concentrate

Abstract: The effect of leaching conditions on the enriching iron was studied after pre-treatment of pyrite cinder. And the influence of acid leaching temperature, leaching time, $\mathrm{pH}$ value and the ratio of liquid to solid on enriching iron was done. The results show that, when the acid leaching temperature was $20^{\circ} \mathrm{C}$, the reaction time was $10 \mathrm{mins}$, the $\mathrm{pH}$ value was 1.5 , and the ratio of liquid to solid was 6 , the iron content in pyrite cinder reached $60.4 \%$, and the sulfur content was $0.227 \%$, which would meet the requirements of raw material for iron-making.

\section{Introduction}

The pyrite cinder was the industrial waste residue, stemmed from the process of making sulfuric acid by roasting pyrites. There are about $0.8 \sim 1.0 \mathrm{t}$ pyrite cinder being brought about when $1 \mathrm{t}$ sulfuric acid was produced. According to statistics, there was about 20 million tons of pyrite cinder being discharged annually in domestic. Such a huge amount of pyrite cinder would occupy lots of land resources, pollute water and atmosphere and do harm to the human body. With the enhancement of people's awareness of environmental protection, recycling waste to treasure, reducing the pollution to the environment and generate economic benefits had become the consensus of the people.

The recycling use of pyrite cinder were mainly reflected in these aspects, being as cement and building materials ${ }^{[1-2]}$, recycling the valuable precious metals ${ }^{[3-5]}$, producing sponge iron and ferric chloride $^{[4-7]}$, preparing radiation shielding materials ${ }^{[8]}$ and preparing iron ore concentrate ${ }^{[9-10]}$ as well. If the pyrite cinder must be of complex utilization on a massive scale, it was a effective method to make it into iron ore concentrate with high grade for iron-making, the recycling usage problem of pyrite cinder could be resolved from the root only by this way. There are still a small quantity of residual sulphur in the pyrite cinder, it was necessary because of the producing process of sulfuric acid by roasting pyrites, the sulphur was harmful for iron-making, it would bring about hot brittleness of steel, decrease the toughness and ductility of steel, especially the anti-impact toughness. In the literature ${ }^{[9]}$, the chemical method was used to deal with the pyrite cinder, and the results showed that the effect of enriching iron and decreasing sulphur was obvious. Therefore, preliminary study about the treatment of pre-roasting had been done to the pyrite cinder collected from Wengfu Group ${ }^{[11]}$, base on these, the effect of the leaching process on the enrich iron would be conducted in this paper, by which it was expected to obtain the iron ore concentrate with high iron content and lower sulphur content, and offer the reference for the comprehensive utilization of pyrite cinder. 


\section{Experiment}

\section{Materials}

In this study, the experimental materials was collected from Guizhou Wengfu Group, they were red powder by eyes. The chemical composition of the pyrite cinder was shown in Table 1 . The pyrite cinder appeared to be a ready source of iron with a iron content of $48.61 \%$ and the Fe content was lower, and the chemical analysis of the sample also revealed that the pyrite cinder contained some impurities such as sulphur.

Table 1 The main chemical composition of pyrite cinders [wt $\%$ ]

\begin{tabular}{cccccccc}
\hline $\mathrm{TFe}$ & $\mathrm{FeO}$ & $\mathrm{SiO}_{2}$ & $\mathrm{CaO}$ & $\mathrm{MgO}$ & $\mathrm{S}$ & $\mathrm{Al}_{2} \mathrm{O}_{3}$ & $\mathrm{P}$ \\
\hline 48.61 & 5.4 & 8.45 & 7.1 & 0.5 & 2.9 & 3.2 & 0.05 \\
\hline
\end{tabular}

\section{Experimental mechanism}

The pyrite cinder contained lots difficult soluble substances, such as silicon dioxide and aluminium oxide. Under high temperature, they would react with sodium hydrate, and they would be transformed into sodium silicate and sodium aluminate. The chemical equations was Eq. 1 and Eq. 2.

$$
\begin{gathered}
2 \mathrm{NaOH}+\mathrm{SiO}_{2}=\mathrm{Na}_{2} \mathrm{SiO}_{3}+\mathrm{H}_{2} \mathrm{O} \\
2 \mathrm{NaOH}+\mathrm{Al}_{2} \mathrm{O}_{3}=2 \mathrm{NaAlO}_{2}+\mathrm{H}_{2} \mathrm{O}
\end{gathered}
$$

Under the weak alkaline environment, there was $10 \%$ sodium carbonate in the aqueous solution, sodium silicate were multiply hydrolyzed into silicates, the reaction equation were from Eq. 3 to Eq. 5 .

The first phase hydrolysis: $\mathrm{Na}_{2} \mathrm{SiO}_{3}+\mathrm{H}_{2} \mathrm{O} \rightarrow \mathrm{H}_{2} \mathrm{SiO}_{4}{ }^{2-}+2 \mathrm{Na}^{+}$

The second phase hydrolysis: $\mathrm{H}_{2} \mathrm{SiO}_{4}{ }^{2-}+\mathrm{H}_{2} \mathrm{O} \rightarrow \mathrm{H}_{3} \mathrm{SiO}_{4}{ }^{-}+\mathrm{OH}^{-}$

The third phase hydrolysis: $\mathrm{H}_{3} \mathrm{SiO}_{4}{ }^{-}+\mathrm{H}_{2} \mathrm{O} \rightarrow \mathrm{H}_{4} \mathrm{SiO}_{4}+\mathrm{OH}^{-}$

Then the silicates were transformed into soluble ions by controlling the $\mathrm{pH}$ of wash solution, and they were wiped off by washing, the residual slag was iron ore concentrate.

\section{Experimental process}

The pyrite cinder was added $10 \% \mathrm{NaOH}$ and $10 \%$ self-made $\mathrm{WJ}$ reagent, then they were mixed well by adding some water. next, they were put in the high temperature resistance furnace, they would stayed for half an hour under $650^{\circ} \mathrm{C}$ and be cooled, then they would be leached for an hour in the solution with $10 \% \mathrm{Na}_{2} \mathrm{CO}_{3}$ aqueous solution. and the leaching slag would be washed by the water with different $\mathrm{pH}$ values, meanwhile, the leaching temperature liquid-solid ratio, leaching time and other conditions were also controlled, after the leaching slag was washed many times, they were dried and the Fe content in it would be analyzed, the aim was to judge the enriching iron effect.

\section{Results and discussion}

\section{Effect of leaching temperature on enriching iron}

The leaching solution was sulfuric acid solution, the $\mathrm{pH}$ was 2.0 , the liquid-solid ratio was 10 , the pyrite cinder pre-treated was leached under $20^{\circ} \mathrm{C}, 30^{\circ} \mathrm{C}, 40^{\circ} \mathrm{C}, 50^{\circ} \mathrm{C}, 60^{\circ} \mathrm{C}$ for half an hour 
respectively, then they were washed, filtrated and dried, at last the iron contain in iron-rich powder would be determined by chemical analysis. and the effect of leaching temperature on enriching iron was shown in Fig. 1.

As seen in Fig. 1, from the angle of dynamics analysis, Brownian movement and rate of chemical reactions were accelerated with the rising temperature. Iron content has a slight rising when the temperature range was from $10^{\circ} \mathrm{C}$ to $20^{\circ} \mathrm{C}$. The main reason was that the dissolving of calcium carbonate accelerated under acid environment with rising temperature. However, when the temperature was above $20^{\circ} \mathrm{C}$, the $\mathrm{Fe}$ content in pyrite cinder decreased continuously. There were two reasons for these phenomena. For one thing, the dissolving of calcium carbonate under acid environment

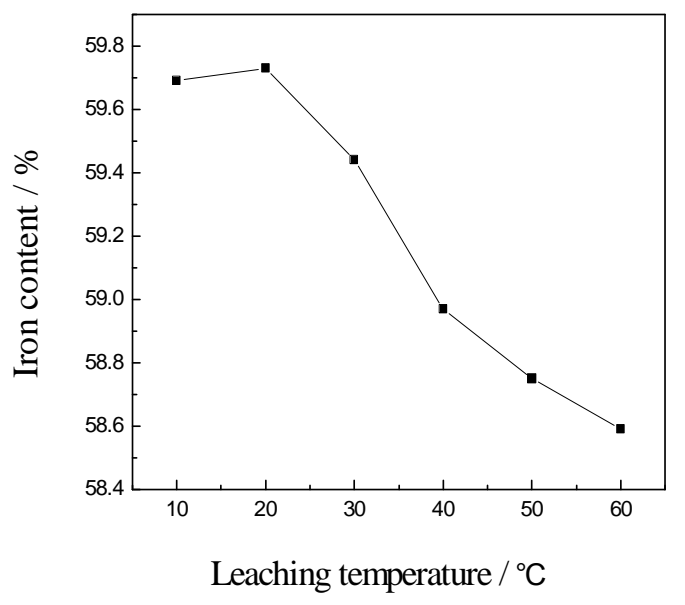

Fig. 1 Effect of leaching temperature on enriching iron generally came to an end at $20^{\circ} \mathrm{C}$ for $0.5 \mathrm{~h}$. but the reactions between ferric oxide and acid were accelerated with rising temperature. For another, the polymerization process of silicate ions was accelerated when the temperature raised, gelatin time was shortened, and the silica stayed in the pyrite cinder increased, so the $20^{\circ} \mathrm{C}$ of temperature for leaching was better after comprehensive consideration.

\section{Effect of pH value on enriching iron}

The leaching solution was sulfuric acid solution, the temperature was $20^{\circ} \mathrm{C}$, the liquid-solid ratio was 10 , the leaching time was half an hour. the pyrite cinder pre-treated was leached when the $\mathrm{pH}$ values was from1.0 to 3.5 , then they were washed, filtrated and dried, at last the iron contain in iron-rich powder would be determined by chemical analysis. and the effect of the pH values on enriching iron was shown in Fig. 2.

As seen in Fig. 2, pH value has an greatly impact on iron content in process of leaching. Iron content raised to $60.4 \%$ slightly with the $\mathrm{pH}$ value from 1 to 1.5 . The main reason was that reactions between ferric oxide and acid was accelerated under the lower $\mathrm{pH}$ value. Iron

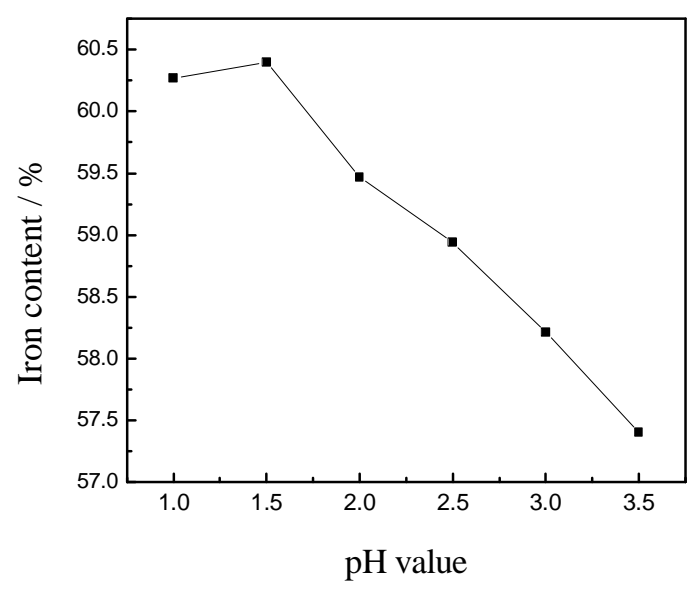

Fig. 2 Effect of $\mathrm{pH}$ value on enriching iron content decreased sharply with rising $\mathrm{pH}$ value owing to the transformation of silicate ions from positive ion to monovalence anion and silicic acid. The rising concentration of $\mathrm{OH}^{-}$in solution promoted the formation of poly silicate. The poly silicate was reticulate cubic structure and it owned strong adsorption capacity, it was firmly adsorbed in pyrite cinder when it was mixed with pyrite cinder. which would lead to the decrease of iron content ultimately. Therefore, $\mathrm{pH}$ value of 1.5 for leaching was better in this study after comprehensive consideration.

\section{Effect of leaching time on enriching iron}

The leaching solution was sulfuric acid solution, the temperature was $20^{\circ} \mathrm{C}$, the liquid-solid ratio was 10 , the $\mathrm{pH}$ value was 1.5 , the pyrite cinder pre-treated was leached when the leaching time 
was from $10 \mathrm{~min}$ to $60 \mathrm{~min}$, then they were washed, filtrated and dried, at last the iron contain in iron-rich powder would be determined by chemical analysis. and the effect of the leaching time on enriching iron was shown in Fig. 3.

As seen in Fig. 3, iron content was $60.51 \%$ when the leaching time was $10 \mathrm{~min}$. With extension of leaching time, iron content experienced continuous declination. There were maybe three reasons for this problem. Firstly, with extension of leaching time, iron content was declined due to continuous reactions between ferric oxide and acid. Secondly, prolonging leaching time was beneficial for formation of poly-silicate acid. Finally, there would promote the formation of $\mathrm{CaSO}_{4} \cdot 2 \mathrm{H}_{2} \mathrm{O}$. So the $10 \mathrm{~min}$ for leaching was better after comprehensive consideration.

\section{Effect of liquid- solid ratio on enriching iron}

The leaching solution was sulfuric acid solution, the temperature was $20^{\circ} \mathrm{C}$, the leaching time was $10 \mathrm{~min}$, the $\mathrm{pH}$ value was 1.5 , the pyrite cinder pre-treated was leached when liquid-solid ratio was from 6 to 14, then they were washed, filtrated and dried, at last the iron contain in iron-rich powder would be determined by chemical analysis. and the effect of the liquid-solid ratio on enriching iron was shown in Fig. 4.

As seen in Fig. 4, iron content increased to $60.4 \%$ and it had met the requirements of raw material for iron-making. With the rising of liquid-solid ratio, the increasing trend was gentle. Iron content was $60.57 \%$ when the liquid-solid ratio reach 14 . There were several reasons for this phenomenon. At first, the crystallizing time of $\mathrm{CaSO}_{4} \cdot 2 \mathrm{H}_{2} \mathrm{O}$ was lengthened because of the

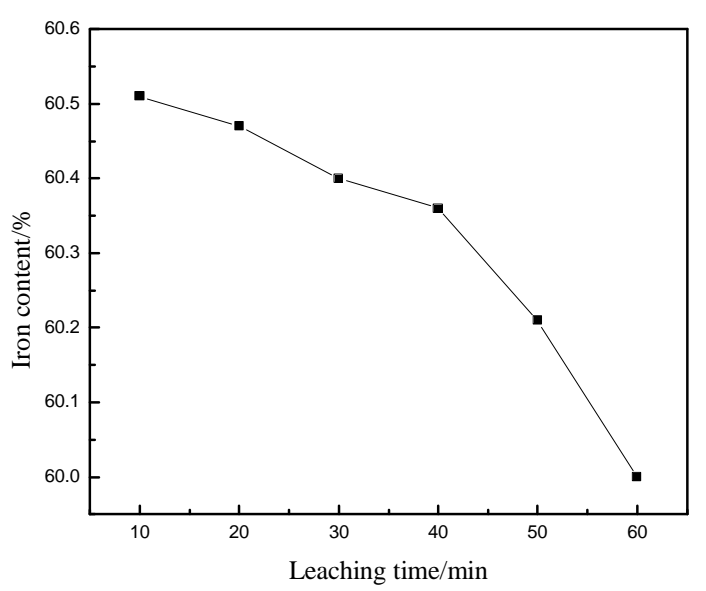

Fig.3 Effect of leaching time on enriching iron

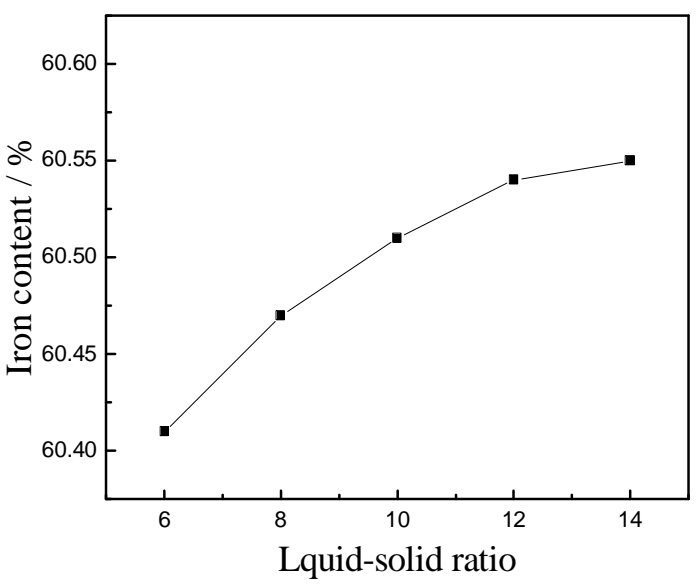

Fig. 4 Effect of liquid to solid ratio on enriching iron reaction between acid and $\mathrm{CaCO}_{3}$. What was more, the cationization process of silicate ions were promoted with the rising of liquid-solid ratio. Finally, concentration of $\mathrm{SiO}_{2}$ decreased and the polymerization of silicate ions slowed down. So the liquid-solid ratio of 6 was better in this study.

\section{Analysis of iron ore concentrate}

A confirmatory experiment was carried out according to the optimum conditions got from above experiments. The iron contain in iron-rich powder will be determined by chemical analysis. The results was shown in Table 2.

Table 2 The main chemical composition of iron ore concentrate (wt\%)

\begin{tabular}{ccccccc}
\hline $\mathrm{TFe}$ & $\mathrm{SiO}_{2}$ & $\mathrm{CaO}$ & $\mathrm{S}$ & $\mathrm{Al}_{2} \mathrm{O}_{3}$ & $\mathrm{P}$ & recovery rate of iron $/ \%$ \\
\hline 60.41 & 4.5 & 1.6 & 0.227 & 0.3 & - & $95.2 \%$ \\
\hline
\end{tabular}


As seen in Table 3, a majority of gangue were removed from pyrite cinder, but there were still $4.5 \% \mathrm{SiO}_{2}$ in it, the main reason maybe was that there existed ore parcel between hematite and gangue. All the same, Iron content in iron ore concentrate could meet the requirements of raw material for iron-making after treating by this technology.

\section{Conclusions}

The $\mathrm{pH}$ value of acid leaching solution increased from 1 to 1.5 , the silicate did not polymerize but still existed in the form of monovalent cations, and dissolving effect of the acid on the iron element was slight, so the Fe content of iron ore concentrate could reach the maximum value of $60.4 \%$. When the $\mathrm{pH}$ value reached 3, the acidity decreased, but the silicate ions had begun to transform into mono-anions and increased the risk of polymerization. The Fe content decreased to $58.2 \%$ when $\mathrm{pH}$ value was 3 , so the $\mathrm{pH}$ value should be controlled strictly. The acid leaching time, temperature, liquid-solid ratio all had a certain influence on the formation of poly-silicate acid. After the single factor tests, the optimum process conditions was obtained. The leaching temperature was $20^{\circ} \mathrm{C}$, leaching time was $10 \mathrm{~min}$, the $\mathrm{pH}$ value was 1.5 and the liquid-solid ratio was 6 , under this condition, the content of iron in the pyrite cinder reached $60.41 \%$ and the sulfur content was $0.227 \%$, which would meet the requirements of raw material for iron-making.

\section{Acknowledgements}

This work was financially supported by Science and Technology Cooperation Project of Guizhou Province (Qian Ke He LH Zi[2015]7656).

\section{References}

[1] Qian Ling, Hou Haobo: The study and manufacture of waste gypsum and pyrite cinder brick. Brick and tile. (2005), p. 8-9, in Chinese

[2] Hao Xiaobin: Study on preparation of soft ferrite materials by pyrite cinder, (2007), Wuhan University Of Technology, WuHan, in Chinese

[3] Y.A.Attja. Using the bacteria to recovery the useful metals from pyrite railings containing gold. Hydrometallurgy, (2002), vol. 22, p.191-300.

[4] You Dahai, Zhang Yahui, Long Xiang etc.: Research on sulfatizing roasting- chloridizing leaching of pyrite cinder containing Au, Noble metal, (2014), Vol.35, p.19-22, in Chinese

[5] Chunxia Yang, Yongheng Chen, Ping'an Peng etc.: Trace element transformations and partitioning during the roasting of pyrite ores in the sulfuric acid industry. Journal of Hazardous Materials, (2009), Vol. 167, p.835-845

[6] HongLiu, ZanYonghong TangDaowen: Experimental study on preparing ferric chlorid i using industrial waste acid and sulfuric acid residue. Journal of Guizhou Normal University (NATURAL SCIENCE EDITION), (2012), p.94-96, in Chinese

[7] Gong Zhuqing, Huang Jian: Preparation of alpha- $\mathrm{Fe}_{2} \mathrm{O}_{3}$ for soft magnetic using ferrous sulfate from pyrite cinder. Environment engineering , (2003), p.48-51, in Chinese

[8] WangYe, Zhang Xiaowen: Preparation and effect evaluation of the radiation shielding materials by sulfuric acid residue. Journal of University of South China (NATURAL SCIENCE EDITION), (2015), Vol. 29, p.37-40, in Chinese 
[9] Wu Delli, Zhu Shenhong, Ma Luming: A new process of treatment for pyrite cinder by chemical method, Comprehensive utilization of mineral resources, (2005), p.34-38, in Chinese

[10] Anping Liu, Wen Ni, Wei Wu: Mechanism of separating pyrite and dolomite by flotation. Journal of University of Science and Technology Beijing, (2007), Vol.14, p.291-296

[11] Li Guowang, Wang Jiawei, Zhao Pingyuan etc.: Experimental study on iron enrichment in sulfuric acid slag. hydrometallurgy, (2014), Vol.33, p.466-468, in Chinese 